AperTO - Archivio Istituzionale Open Access dell'Università di Torino

Killer cell immunoglobulin-like receptor ligand mismatching and outcome after haploidentical transplantation with post-transplant cyclophosphamide

This is a pre print version of the following article:

Original Citation:

Availability:

This version is available http://hdl.handle.net/2318/1704217 since 2019-06-10T16:00:26Z

Published version:

DOI:10.1038/s41375-018-0170-5

Terms of use:

Open Access

Anyone can freely access the full text of works made available as "Open Access". Works made available under a Creative Commons license can be used according to the terms and conditions of said license. Use of all other works requires consent of the right holder (author or publisher) if not exempted from copyright protection by the applicable law. 


\title{
Killer cell immunoglobulin-like receptor ligand mismatching and outcome after haploidentical transplantation with post-transplant cyclophosphamide
}

\author{
Avichai Shimoni ${ }^{1} \cdot$ Myriam Labopin $^{2} \cdot$ Francesca Lorentino $^{3} \cdot$ Maria Teresa Van Lint $^{4} \cdot$ Yener Koc $^{5} \cdot$ Zafer Gülbas $^{6}$. \\ Johanna Tischer ${ }^{7} \cdot$ Benedetto Bruno $^{8} \cdot$ Didier Blaise $^{9} \cdot$ Pietro Pioltelli $^{10} \cdot$ Boris Afanasyev $^{11} \cdot$ Fabio Ciceri $^{3}$. \\ Mohamad Mohty ${ }^{12} \cdot$ Arnon Nagler $^{1,2}$
}

\section{Abstract}

Haploidentical stem cell transplantation with $\mathrm{T}$ cell-replete grafts and post-transplant cyclophosphamide (PTCy) is increasingly used with encouraging outcome. Natural killer (NK) cell alloreactivity, predicted by missing killer cell immunoglobulin-like receptor (KIR) ligands in the recipient that are present in their donor improves outcome of $\mathrm{T}$ celldepleted haploidentical transplants. We explored the role of KIR ligand mismatching in 444 acute leukemia patients after T cell-replete transplants with PTCy. Thirty-seven percent of all patients had KIR ligand mismatching. Patients were in first remission (CR1) (39\%), second remission (CR2) (26\%), or active disease (35\%). Stem cell source was peripheral blood (PBSC, 46\%) or bone marrow (54\%). The 2-year relapse, non-relapse mortality (NRM), and survival rates were $36.0 \%$ (95\% confidence interval (CI), 31.4-40.7), 23.9\% (20.0-28.0), and 45.9\% (40.8-51.0), respectively. Multivariate analysis identified acute myeloid leukemia compared with acute lymphoblastic leukemia (hazard ratio (HR) $0.55, P=0.002$ ), female gender (HR 0.72, $P=0.04$ ), and good performance status (HR 0.71, $P=0.04$ ) as factors associated with better survival, while advanced age (HR 1.13, $P=0.04$ ), active disease (HR 3.38, $P<0.0001$ ), and KIR ligand mismatching (HR 1.41, $P=0.03$ ) as associated with worse survival. KIR ligand mismatching was associated with a trend for higher relapse but not with graft-versus-host disease or NRM. The KIR ligand-mismatching effect was more prominent in patients given PBSC. In conclusion, there is no evidence that KIR ligand mismatching results in better outcome in the PTCy setting.

* Avichai Shimoni

ashimoni@sheba.health.gov.il

1 Division of Hematology, Chaim Sheba Medical Center, TelHashomer and Sackler Medical School, Tel-Aviv University, TelAviv, Israel

2 Acute Leukemia Working Party Office, Paris, France

3 Hematology and Bone Marrow Transplant Unit, San Raffaele Scientific Institute, Milan, Italy

4 Department of Haematology II, Ospedale San Martino, Genova, Italy

5 Stem Cell Transplant Unit, Medical Park Hospitals, Antalya, Turkey

6 Bone Marrow Transplantation Department, Anadolu Medical Center Hospital, Kocaeli, Turkey
${ }^{7}$ Department of Internal Medicine III, LMU Munich Campus Grosshadern, Munich, Germany

${ }^{8}$ S.S.C.V.D. Trapianto di Cellule Staminali A.O.U. Citta della Salute e della Scienza di Torino, Torino, Italy

${ }^{9}$ Programme de Transplantation and Therapie Cellulaire, Centre de Recherche en Cancérologie de Marseille, Institut Paoli Calmettes, Marseille, France

${ }^{10}$ Ospedale San Gerardo, Clinica Ematologica dell'Universita Milano-Biocca, Monza, Italy

${ }^{11}$ First State Pavlov Medical University of St. Petersburg, Raisa Gorbacheva Memorial Research, Institute for Paediatric Oncology, Hematology and Transplantation, St Petersburg, Russia

${ }^{12}$ Hématologie Clinique et Thérapie Cellulaire, Hôpital SaintAntoine, Paris, France 



\section{Introduction}

Allogeneic hematopoietic stem cell transplant (SCT) is a potentially curative treatment for acute myeloid leukemia (AML) and acute lymphoblastic leukemia (ALL). Only about $1 / 3$ of patients who require SCT have an available human leukocyte antigen (HLA)-matched sibling donor. A haploidentical-related donor can be identified in almost all patients. A haploidentical donor is most often readily available with no delays attributed to donor search, and can be easily approached for further stem cell or cellular therapies as needed.

The initial results of haploidentical transplant using protocols that were similar to HLA-matched donor transplants were associated with a high risk for graft failure and severe graft-versus-host disease (GVHD) resulting in prohibitive non-relapse mortality (NRM) rate and dismal survival $[1,2]$. A regimen using extensive $T$ cell depletion of donor graft, supplemented with the infusion of high stem cell dose and no post-transplant immune-suppressive therapy was able to overcome the HLA barrier of engraftment and GVHD, but was still associated with high NRM, due to slow immune reconstitution and infections [3]. Several post-transplant cellular therapies were explored trying to improve outcome; however, they require high level of expertise, are very costly, and cannot be applied in most transplant centers.

Over the last decade, novel approaches using $\mathrm{T}$ cellreplete grafts were introduced. The most experience was gained by the use of post-transplant cyclophosphamide (PTCy) [4] and by the use of granulocyte-colonystimulating factor (G-CSF)-primed marrow and peripheral blood stem cell (PBSC) harvesting and in vivo $\mathrm{T}$ cell depletion with anti-thymocyte globulin (ATG) and intensive post-transplant immune suppression (The Beijing Approach) [5]. These simple but effective methods have allowed a marked increase in the use of haploidentical donors in recent years [6]. Several retrospective comparative studies have shown that these $\mathrm{T}$ cell-replete haploidentical transplant are associated with comparable outcomes with HLA-matched sibling and unrelated donor transplants (reviewed in [7, 8]).

Most patients will have more than one available haploidentical donors and several algorithms have been developed to select the best donor [7, 9-12]. These algorithms considered donor age, gender, and family relations, as well as HLA and blood group compatibility, CMV status, and the finding of host donor-specific antibodies as important factors. Natural killer (NK) cell alloreactivity has a documented role in haploidentical $\mathrm{T}$ cell-depleted SCT $[13,14]$. NK cells are an essential part of the innate immune system directed against malignancy and infections $[15,16]$. NK cell function is regulated by a complex of inhibitory and activating receptors as well as co-modulating receptors. The main receptors belong to the killer cell immunoglobulin-like receptor (KIR) family. The major ligands for inhibitory KIRs belong to HLA C and are grouped as $\mathrm{C}$ group 1 and $\mathrm{C}$ group 2, based on polymorphism at residue 80 in the HLA $\mathrm{C}$ molecule or to Bw4 epitopes. When an inhibitory KIR engages its ligand, the NK cell becomes inhibited. Leukemia cells and infected cells often down-regulate HLA and thus become susceptible to killing by NK cells. Donor NK cells may become activated against host cells when the host lacks a ligand that is present in the donor (missing self model). KIR ligand mismatching in the graft-versus-host direction was associated with lower relapse rates as well as better engraftment and lower rates of GVHD in T celldepleted haploidentical transplants [13, 14]. However, there is limited data on the role of NK alloreactivity in T cellreplete haploidentical transplants [17-21].

In this study, we show in a relative large registry study of haploidentical transplants with PTCy that KIR ligand mismatching may be associated with a worse outcome, especially in patients having PBSC transplants, and haploidentical donors with KIR ligand mismatching should not be preferred.

\section{Patients and methods}

\section{Study design and data collection}

This is a retrospective multicenter analysis. Data were provided and approved for this study by the Acute Leukemia Working Party of the European Society for Blood and Marrow Transplantation (EBMT). The latter is a voluntary working group of more than 500 transplant centers that are required to report all consecutive SCTs and follow-ups once a year. Audits are routinely performed to determine the accuracy of the data. The study protocol was approved by the institutional review board at each site and complied with country-specific regulatory requirements. The study was conducted in accordance with the Declaration of Helsinki and Good Clinical Practice guidelines. All patients provided written informed consent authorizing the use of their personal information for research purposes. Eligibility criteria included patients with de novo AML or ALL in any disease status at SCT, following transplants from haploidentical relative (with at least two HLA mismatches) between the years 2009 and 2015. GVHD prophylaxis included posttransplant high-dose cyclophosphamide in all patients. Grafts were from the bone marrow (BM) or PBSC and were all $\mathrm{T}$ cell replete. Ex-vivo T cell depletion was not allowed. HLA typing was based on high-resolution typing of class I and class II HLA antigens. Patient KIR ligand typing was defined according to HLA typing. Patients were divided 
into a group with and a group with no KIR ligand mismatching in the graft-versus-host direction as previously described. Patient and donor KIR genotyping was not available. Variables collected included recipient and donor characteristics, disease features, transplant-related factors including drugs and total doses used in the conditioning regimen, and outcome variables.

\section{Conditioning regimens}

The conditioning regimen was selected according to the participating center discretion. Dose intensity was defined according to standard criteria based on the reversibility and expected duration of cytopenia after SCT [22]. GVHD prophylaxis was selected according to the participating center policy and consisted of a calcineurin inhibitor (cyclosporine A or tacrolimus) and mycophenolate mofetil in addition to PTCy in most patients. ATG was allowed according to the participating center policy.

\section{Evaluation of outcomes}

Disease relapse was defined according to standard hematological criteria. NRM was defined as death of any cause in the absence of prior disease recurrence. Leukemia-free Survival (LFS) was defined as survival without relapse. Overall survival (OS) was calculated from the day of SCT until death of any cause or last follow-up. Patients with no event were censored at last contact. The cause of death was categorized according to standard criteria. The cause of death of patients who experienced relapsed disease at any time prior to death was considered relapse related. Acute and chronic GVHD were graded according to standard criteria.

\section{Statistical analysis}

The primary end point of the study was OS. Secondary endpoints included acute and chronic GVHD, NRM, relapse incidence, and LFS. All outcomes were measured from the time of stem cell infusion. The two patient KIR ligand groups were compared by the $X^{2}$ method for qualitative variables, and Mann-Whitney test for continuous parameters. LFS and OS were estimated using the KaplanMeier method [23], while NRM, relapse, and GVHD were estimated using cumulative incidence analysis considering competing risks [24]. Univariate comparisons were done using the log-rank test for LFS and OS, and Gray's test for GVHD, relapse incidence (RI), and NRM. For all univariate analyses, continuous variables were categorized and the median was used as a cut-off point. Multivariate analyses were performed using Cox propor- tional hazards. Variables were included in the multivariate
Table 1 Patient characteristics

\begin{tabular}{|c|c|c|c|}
\hline & $\begin{array}{l}\text { KIR mismatched } \\
(n=165)\end{array}$ & $\begin{array}{l}\text { KIR matched } \\
(n=279)\end{array}$ & $P$ value \\
\hline $\begin{array}{l}\text { Age (median, } \\
\text { range), years }\end{array}$ & 47 (19-78) & $46(18-75)$ & 0.48 \\
\hline Gender (male) & $59 \%$ & $60 \%$ & 0.91 \\
\hline \multicolumn{4}{|l|}{ Diagnosis } \\
\hline AML & $73 \%$ & $74 \%$ & \multirow[t]{2}{*}{0.74} \\
\hline ALL & $27 \%$ & $26 \%$ & \\
\hline \multicolumn{4}{|l|}{ Disease status } \\
\hline CR1 & $36 \%$ & $41 \%$ & \multirow[t]{3}{*}{0.36} \\
\hline $\mathrm{CR} 2$ & $25 \%$ & $26 \%$ & \\
\hline Active disease & $39 \%$ & $33 \%$ & \\
\hline \multicolumn{4}{|l|}{ CMV status } \\
\hline $\mathrm{D}-/ \mathrm{R}-$ & $11 \%$ & $10 \%$ & \multirow[t]{4}{*}{0.16} \\
\hline $\mathrm{D}+/ \mathrm{R}+$ & $9 \%$ & $8 \%$ & \\
\hline $\mathrm{D}-/ \mathrm{R}+$ & $13 \%$ & $21 \%$ & \\
\hline $\mathrm{D}+/ \mathrm{R}+$ & $67 \%$ & $61 \%$ & \\
\hline $\begin{array}{l}\text { Performance status } \\
(\mathrm{KS} \geq 90)\end{array}$ & $68 \%$ & $63 \%$ & 0.35 \\
\hline $\begin{array}{l}\text { Donor age (median, } \\
\text { range), years }\end{array}$ & $40(13-74)$ & $37(13-72)$ & 0.15 \\
\hline $\begin{array}{l}\text { Donor gender } \\
\text { (male) }\end{array}$ & $55 \%$ & $57 \%$ & 0.65 \\
\hline \multicolumn{4}{|l|}{ Stem cell source } \\
\hline BM & $54 \%$ & $53 \%$ & \multirow[t]{2}{*}{0.91} \\
\hline PBSC & $46 \%$ & $47 \%$ & \\
\hline \multicolumn{4}{|l|}{ Conditioning regimen } \\
\hline MAC & $58 \%$ & $51 \%$ & \multirow[t]{2}{*}{0.17} \\
\hline RIC & $42 \%$ & $49 \%$ & \\
\hline \multicolumn{4}{|l|}{ GVHD prophylaxis } \\
\hline $\mathrm{CSA}+\mathrm{MMF}$ & $45 \%$ & $48 \%$ & \multirow[t]{4}{*}{0.15} \\
\hline MMF + Siro & $10 \%$ & $6 \%$ & \\
\hline MMF + Tacro & $40 \%$ & $37 \%$ & \\
\hline Other & $5 \%$ & $9 \%$ & \\
\hline $\begin{array}{l}\text { Time from } \\
\text { diagnosis (median, } \\
\text { range) }\end{array}$ & $8(2-146)$ & $8(2-119)$ & 0.9 \\
\hline $\begin{array}{l}\text { Year of SCT } \\
\text { (median, range) }\end{array}$ & $\begin{array}{l}2013 \\
(2009-2015)\end{array}$ & $\begin{array}{l}2013 \\
(2009-2015)\end{array}$ & 0.58 \\
\hline
\end{tabular}

KIR killer immunoglobulin-like receptor, $A M L$ acute myeloid leukemia, $A L L$ acute lymphoblastic leukemia, $D$ donor, $R$ recipient, $K S$ Karnofsky performance score, GVHD graft-versus-host disease, $B M$ bone marrow, $P B S C$ peripheral blood stem cells, $M A C$ myeloablative conditioning, RIC reduced-intensity conditioning, CSA cyclosporine A, $M M F$ mycophenolate mofetil, Siro sirolimus, Tacro tacrolimus, SCT stem cell transplantation

model if they were conceptually important or if they differ in terms of distribution between the two groups. Results are expressed as hazard ratio (HR) with 95\% confidence interval (CI). Analyses were also stratified by disease (AML or ALL) and source of stem cells. To test for a center effect, 
we introduced a random effect or frailty for each centerinto the model. All $p$ values were two-sided and values $<0.05$ were considered statistically significant. Statistical analyses were performed with SPSS 22.0 (IBM Corp., Armonk, NY, USA) and R3.2.3 software packages (R Development Core Team, Vienna, Austria).

\section{Results}

\section{Patient characteristics}

The study included 444 patients with AML $(n=327)$ or ALL $(n=117)$ given haploidentical transplant with PTCy during the years 2009-2015. Patient characteristics are outlined in Table 1 . The median age was 46 years (range, 18-78 years). The median donor age was 39 years (range, 13-74 years) and $24 \%$ of transplants were from a female donor to a male recipient. The median time from diagnosis to transplantation was 8 months (range, 2-146 months). Patients were in first remission (CR1) (39\%), second remission (CR2) (26\%), or active disease (35\%) at the time of transplantation. Stem cell source was PBSC (46\%) or BM (54\%). The conditioning regimen was myeloablative conditioning (MAC, 54\%) or reduced-intensity conditioning (RIC, 46\%). The GVHD prevention regimen included cyclosporine or tacrolimus with mycophenolate, in addition to PTCy in $85 \%$ of patients.

HLA typing of recipients and donors showed that 105 patients $(25 \%)$ lacked an HLA C group 1 or 2 antigen that was present in the donor. Seventy-nine patients $(15 \%)$ lacked a Bw4 antigen that was present in their donor. In all,
165 patients (37\%) had KIR ligand mismatching in the graft-versus-host direction according to the missing self model. There was no difference in patient characteristics between patients with or without KIR ligand mismatching (Table 1). We have also analyzed KIR ligand mismatching according to the missing ligand model, which considered only host missing ligands, irrespective of their expression in the donor. In all, 331 patients (69\%) missed at least one C group 1, C group 2, or Bw4 ligand. The missing ligand theory did not explain any of the transplantation outcomes and will not be further discussed.

\section{Engraftment and GVHD}

Patients (92.3\%) had neutrophil engraftment with a median time to engraftment of 18 days (range, 8-47 days). The rate of engraftment was $93.2 \%$ in KIR ligand-matched and $89.9 \%$ in KIR ligand-mismatched recipients $(P=0.44)$. The median time to engraftment was 18 days (range, 1147 days) and 18 days (range, $8-34$ days), respectively ( $P=$ $0.87)$.

The cumulative incidence of acute GVHD grade II-IV was $28.3 \%$ (95\% CI, 24.5-32.3). Multivariate analysis identified PBSC transplantation compared to BM (HR 2.10, $P=0.0004)$ and transplantation from a female donor (HR $1.42, P=0.07)$ as factors predicting for increased rates of acute GVHD (Table 2). Acute GVHD was less common in patients with AML compared to ALL (HR 0.63, $P=0.03$ ). The rate of acute GVHD grade II-IV was $24.1 \%$ (95\% CI, 17.6-31.1) and 32.2\% (95\% CI, 26.7-37.9) in patients with and without KIR ligand mismatching, respectively $(P=$ 0.08). However, KIR ligand mismatching was not an

Table 2 Multivariate analysis of pre-transplant factors predicting for acute and chronic GVHD

\begin{tabular}{|c|c|c|c|c|}
\hline \multirow[t]{2}{*}{ Factor } & \multicolumn{2}{|c|}{ Acute GVHD grade II-IV } & \multicolumn{2}{|l|}{ Chronic GVHD } \\
\hline & $\mathrm{HR}(95 \% \mathrm{CI})$ & $P$ value & $\mathrm{HR}(95 \% \mathrm{CI})$ & $P$ value \\
\hline Age (per 10 years) & $0.98(0.86-1.11)$ & 0.72 & $0.91(0.76-1.08)$ & 0.27 \\
\hline Gender (female Vs male) & $1.27(0.88-1.85)$ & 0.21 & $0.72(0.48-1.19)$ & 0.23 \\
\hline Diagnosis (AML vs ALL) & $0.63(0.41-0.96)$ & 0.03 & $1.19(0.95-1.49)$ & 0.13 \\
\hline CR2 vs. CR1 & $1.27(0.79-2.03)$ & 0.32 & $0.84(0.50-1.42)$ & 0.52 \\
\hline Advanced vs. CR1 & $1.37(0.86-2.18)$ & 0.19 & $1.17(0.64-2.14)$ & 0.61 \\
\hline $\mathrm{KPS} \geq 90$ & $1.10(0.73-1.65)$ & 0.66 & $0.74(0.45-1.21)$ & 0.23 \\
\hline Donor gender (Female vs. male) & $1.42(0.97-2.06)$ & 0.07 & $0.92(0.58-1.47)$ & 0.72 \\
\hline KIR mismatching (mismatched vs. matched) & $0.73(0.48-1.09)$ & 0.12 & $0.87(0.53-1.44)$ & 0.59 \\
\hline Stem cell source (PBSC vs BM) & $2.10(1.40-3.16)$ & 0.0004 & $1.04(0.53-2.01)(4$ & 0.92 \\
\hline Conditioning regimen ( $R I C$ vs MAC) & $0.76(0.51-1.16)$ & 0.20 & $0.81(0.46-1.43)$ & 0.47 \\
\hline \multicolumn{5}{|l|}{ GVHD prophylaxis } \\
\hline Tacro + MMF (vs CSA+MMF) & $0.88(0.57-1.36)$ & 0.56 & $1.87(0.79-4.40)$ & 0.15 \\
\hline Other & $0.96(0.56-1.64)$ & 0.88 & $2.07(0.91-4.73)$ & 0.08 \\
\hline Center (frailty variable) & & 0.92 & & 0.007 \\
\hline
\end{tabular}

$A M L$ acute myeloid leukemia, $A L L$ acute lymphoblastic leukemia, $G V H D$ graft-versus-host disease, $C R 1$ first remission, $C R 2$ second remission, KPS Karnofsky performance score, $B M$ bone marrow, $P B S C$ peripheral blood stem cells, KIR killer immunoglobulin-like receptor, $M A C$ myeloablative conditioning, $R I C$ reduced-intensity conditioning, $C S A$ cyclosporine A, $M M F$ mycophenolate mofetil, Tacro tacrolimus, $H R$ hazard ratio, $C I$ confidence interval 


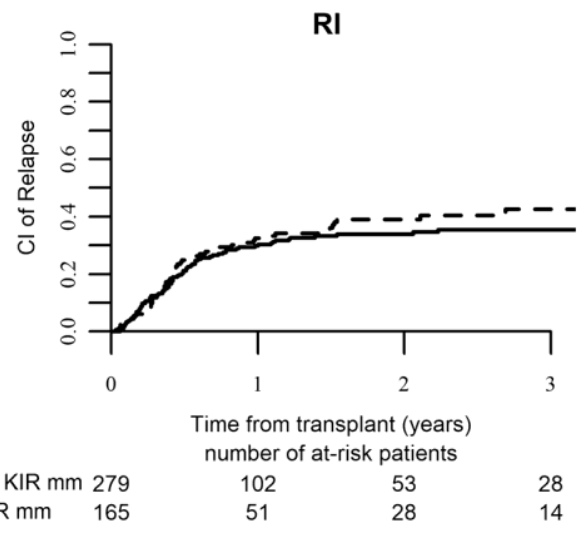

LFS

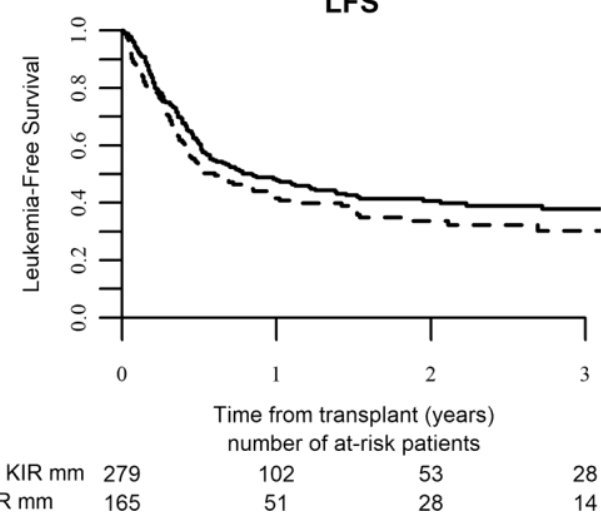

Fig. 1 Transplantation outcomes after T cell-replete haploidentical transplant in the entire patient group $(n=444)$. Cumulative incidence curves of relapse incidence (RI) and non-relapse mortality (NRM) and Kaplan-Meier curves of overall survival (OS) and leukemia-free

independent factor in the multivariate analysis (HR 0.73, $P$ $=0.12$ ).

The cumulative incidence of chronic GVHD was $33.3 \%$ (95\% CI, 28.6-38). The multivariate analysis could not identify any significant predicting factor for chronic GVHD (Table 2). In particular, KIR ligand mismatching was not associated with chronic GVHD (HR 0.87, $P=0.59$ ).

\section{Relapse and non-relapse mortality}

The 2-year relapse and NRM rates in the entire group were $36.0 \%$ (95\% CI, 31.4-40.7) and 23.9\% (95\% CI, 20.0-8.0), respectively (Fig. 1). Multivariate analysis identified disease status at transplantation as the most significant factor predicting relapse (HR 5.17, $P<0.0001$ and HR 1.65, $P=0.06$ for active disease and CR2, respectively, compared with CR1 at transplantation). RIC was associated with higher incidence than MAC (HR 1.57, $P=0.03$ ). There was a trend for higher relapse rates in patients with KIR ligand mismatching (HR 1.36, $P=0.09$ ). This trend was seen in patients with AML (HR 1.48, $P=0.07$ ) but not when the analysis was limited to patients with ALL (HR 0.95, $P=$ 0.88). Relapse was less common in AML compared with
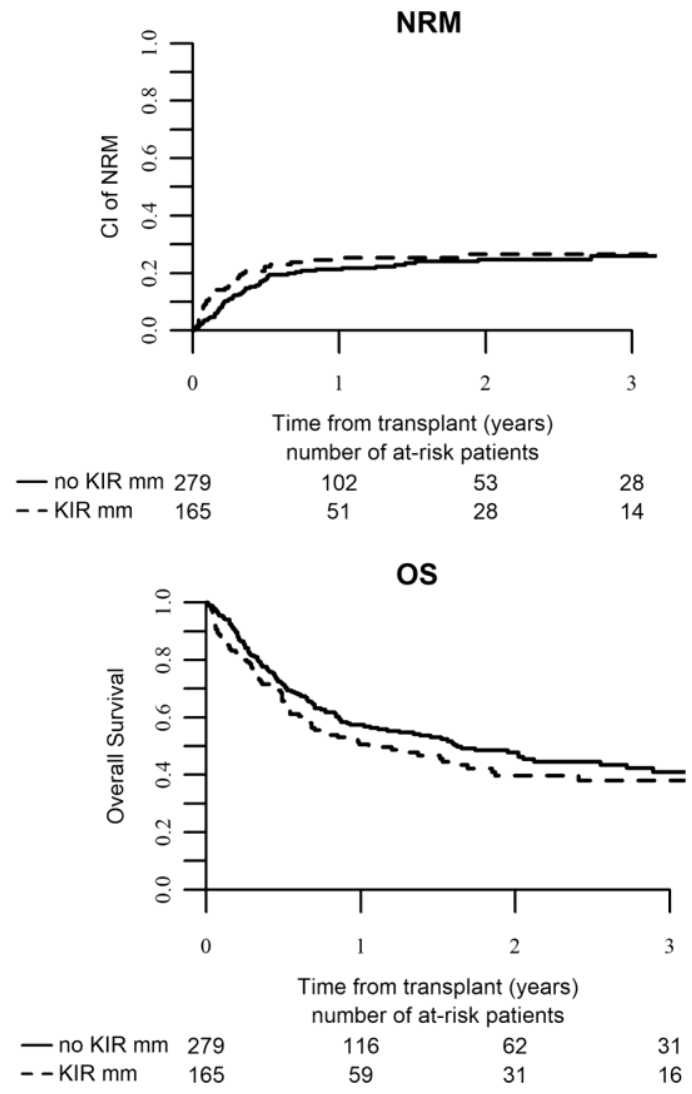

survival (LFS) are compared between patients with KIR ligandmatched donors (solid line) and patients with KIR ligand-mismatched donors in the GVHD direction (dashed line)

ALL (HR 0.64, $P=0.05$ ). RI was also lower in female patients and after transplantation from female donors (Table 3).

The predicting factors for NRM were active disease at transplantation (HR 1.73, $P=0.05)$ and advanced age $(P=$ $1.38, P=0.0004$ ). AML (HR 0.59, $P=0.05$ ), good performance status (HR 0.74, $P=0.07$ ) and PBSC (HR 0.56, $P=0.07)$ were associated with a lower incidence of NRM (Table 3). A strong center effect was also detected in the incidence of NRM $(P=0.001)$. KIR ligand mismatching was not a significant factor for NRM (HR 1.29, $P=0.28$ ).

\section{Leukemia-free survival and overall survival}

With a median follow-up of 14 months (range, 170 months), 236 patients are alive and 208 have died. The LFS and OS rates were $39.2 \%$ (95\% CI, 34.3-44.1) and $45.9 \%$ (95\% CI, 40.8-51.0), respectively. The majorcauses of death were disease recurrence $(n=82)$, GVHD $(n=28)$, infection $(n=68)$, and others $(n=30)$. The status of disease at transplantation was the most important factor predicting OS. The 2-year OS was $66.8 \%$ (95\% CI, 59.4-74.3), 56.6\% (95\% CI, 47.4-65.9), and 28.8\% (95\% CI, 21.0-36.5) in 
Table 3 Multivariate analysis of pre-transplant factors predicting for relapse and non-relapse mortality

\begin{tabular}{|c|c|c|c|c|}
\hline \multirow[t]{2}{*}{ Factor } & \multicolumn{2}{|l|}{ Relapse } & \multicolumn{2}{|c|}{ Non-relapse mortality } \\
\hline & $\mathrm{HR}(95 \% \mathrm{CI})$ & $P$ value & HR $(95 \%$ CI $)$ & $P$ value \\
\hline Age (per 10 years) & $0.83(0.72-0.95)$ & 0.006 & $1.38(1.16-1.65)$ & 0.0004 \\
\hline Gender (Female vs. male) & $0.61(0.41-0.90)$ & 0.01 & $1.08(0.69-1.68)$ & 0.74 \\
\hline Diagnosis (AML vs. ALL) & $0.64(0.40-1.00)$ & 0.05 & $0.59(0.35-1.00)$ & 0.05 \\
\hline CR2 vs. CR1 & $1.65(0.98-2.76)$ & 0.06 & $0.95(0.53-1.69)$ & 0.86 \\
\hline Advanced vs. CR1 & $5.17(3.23-8.29)$ & $<0.0001$ & $1.73(1.002 .99)$ & 0.05 \\
\hline KPS $\geq 90$ & $0.79(0.54-1.16)$ & 0.22 & $0.74(0.45-1.04)$ & 0.07 \\
\hline Donor gender (Female vs. male) & $0.65(0.45-0.94)$ & 0.02 & $0.89(0.57-1.40)$ & 0.82 \\
\hline KIR mismatching (Mismatched vs. matched) & $1.36(0.94-1.95)$ & 0.09 & $1.29(0.81-2.04)$ & 0.28 \\
\hline Stem cell source (PBSC vs. BM) & $1.21(0.83-1.77)$ & 0.32 & $0.56(0.30-1.06)$ & 0.07 \\
\hline Conditioning regimen (RIC vs. MAC) & $1.57(1.04-2.36)$ & 0.03 & $1.01(0.61-1.66)$ & 0.98 \\
\hline \multicolumn{5}{|l|}{ GVHD prophylaxis } \\
\hline Tacro + MMF (vs. CSA + MMF) & $0.63(0.40-0.97)$ & 0.04 & $1.61(0.82-3.18)$ & 0.17 \\
\hline Other & $1.02(0.59-1.74)$ & 0.95 & $3.89(1.87-8.11)$ & 0.0003 \\
\hline Center (frailty variable) & & 0.92 & & 0.001 \\
\hline
\end{tabular}

$A M L$ acute myeloid leukemia, $A L L$ acute lymphoblastic leukemia, $G V H D$ graft-versus-host disease, $C R 1$ first remission, $C R 2$ second remission, $K P S$ Karnofsky performance score, $B M$ bone marrow, $P B S C$ peripheral blood stem cells, KIR killer immunoglobulin-like receptor, $M A C$ myeloablative conditioning, $R I C$ reduced-intensity conditioning, $C S A$ cyclosporine A, $M M F$ mycophenolate mofetil, Tacro tacrolimus, $H R$ hazard ratio, $C I$ confidence interval

Table 4 Multivariate analysis of pre-transplant factors predicting for leukemia-free survival and overall survival

\begin{tabular}{|c|c|c|c|c|}
\hline \multirow[t]{2}{*}{ Factor } & \multicolumn{2}{|l|}{ LFS } & \multicolumn{2}{|l|}{ OS } \\
\hline & HR $(95 \% \mathrm{CI})$ & $P$ value & HR $(95 \% \mathrm{CI})$ & $P$ value \\
\hline Age (per 10 years) & $1.01(0.91-1.13)$ & 0.80 & $1.13(1.01-1.27)$ & 0.04 \\
\hline Gender (Female vs. male) & $0.74(0.55-0.99)$ & 0.04 & $0.72(0.53-0.99)$ & 0.04 \\
\hline Diagnosis (AML vs. ALL) & $0.59(0.42-0.83)$ & 0.002 & $0.55(0.38-0.80)$ & 0.002 \\
\hline CR2 vs. CR1 & $1.25(0.86-1.83)$ & 0.25 & $1.44(0.96-2.16)$ & 0.08 \\
\hline Advanced vs. CR1 & $3.13(2.20-4.46)$ & $<0.0001$ & $3.38(2.26-5.04$ & $<0.0001$ \\
\hline KPS $\geq 90$ & $0.74(0.55-1.00)$ & 0.05 & $0.71(0.51-0.98)$ & 0.04 \\
\hline Donor gender (Female vs. male) & $0.82(0.62-1.09)$ & 0.17 & $0.81(0.59-1.10)$ & 0.18 \\
\hline KIR mismatching (Mismatched vs. matched) & $1.29(0.97-1.73)$ & 0.08 & $1.41(1.03-1.93)$ & 0.03 \\
\hline Stem cell source (PBSC vs. BM) & $0.89(0.64-1.25)$ & 0.51 & $0.83(0.55-1.23)$ & 0.55 \\
\hline Conditioning regimen (RIC vs. MAC) & $1.28(0.93-1.77)$ & 0.13 & $1.24(0.88-1.76)$ & 0.22 \\
\hline \multicolumn{5}{|l|}{ GVHD prophylaxis } \\
\hline Tacro + MMF (vs. CSA + MMF) & $0.95(0.63-1.43)$ & 0.81 & $1.27(0.79-2.04)$ & 0.32 \\
\hline Other & $1.62(1.03-2.54)$ & 0.04 & $1.95(1.14-3.31)$ & 0.01 \\
\hline Center (frailty variable) & & 0.05 & & 0.005 \\
\hline
\end{tabular}

$A M L$ acute myeloid leukemia, $A L L$ acute lymphoblastic leukemia, $G V H D$ graft-versus-host disease, $C R 1$ first remission, $C R 2$ second remission, KPS Karnofsky performance score, $B M$ bone marrow, PBSC peripheral blood stem cells, KIR killer immunoglobulin-like receptor, $M A C$ myeloablative conditioning, RIC reduced-intensity conditioning, CSA cyclosporine A, MMF mycophenolate mofetil, Tacro tacrolimus, $H R$ hazard ratio, $C I$ confidence interval, $L F S$ leukemia-free survival, $O S$ overall survival

CR1, CR2, and active disease, respectively $(P<0.0001)$. The 2-year OS was $46.8 \%$ (95\% CI, 38.2-55.3) in patients with KIR ligand mismatching and $53.1 \%$ (95\% CI, 46.4$59.7)$ in patients with no KIR ligand mismatching $\quad(P=$ 0.11 , Fig. 1). Multivariate analysis identified AML (compared to ALL) (HR 0.55, $P=0.002$ ), female gender (HR 0.72, $P=0.04$ ), and good performance status (HR $0.71, P=0.04)$ as factors associated with better survival, while advanced age (HR 1.13, $P=0.04$ ), active disease (HR 3.38, $P<0.0001$ ), and KIR ligand mismatching (HR $1.41, P=0.03)$ were factors associated with worse survival (Table 4). A center effect was also evident in predicting OS
$(P=0.005)$. The role of KIR ligand mismatching was more evident in AML. The HRs in multivariate analysis for OS were HR $1.42(P=0.07)$ in AML and HR $1.63(P=0.15)$ in ALL.

The negative effect of KIR ligand mismatching was more prominent in patients given PBSC compared with BM. Among PBSC recipients OS was 51.0\% (95\% CI, 41.8-60.3) and $34.5 \%$ (95\% CI, 21.8-47.2) after KIR ligand-matched and KIR ligand-mismatched transplants (Fig. 2, $P=0.02$ ). This was mostly related to higher relapse rates in the KIR ligand-mismatched group, 46.7\% (34.4-58.2) and 32.2\% (24.1-40.6), respectively $(P=0.05)$. Multivariate analysis 

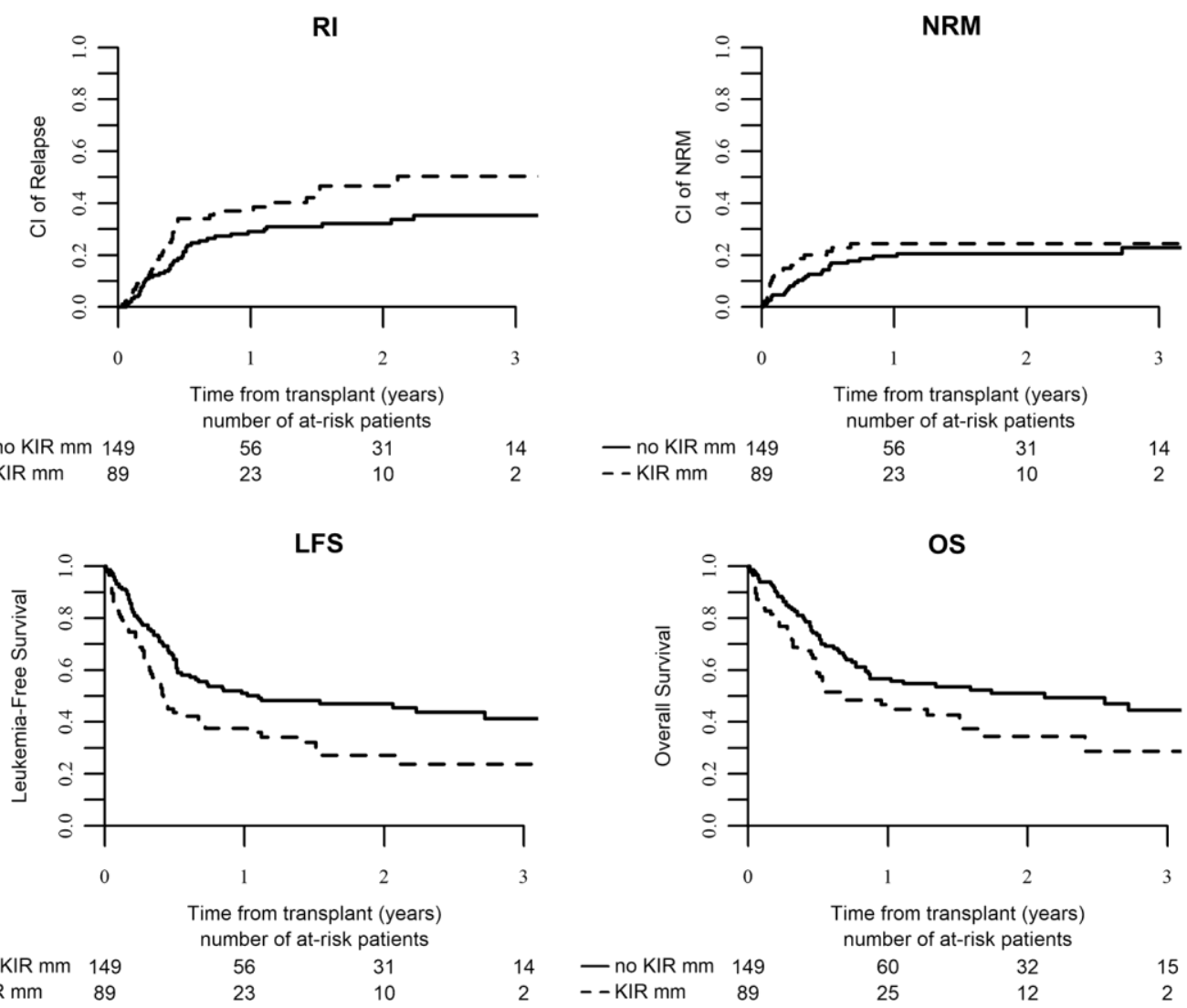

Fig. 2 Transplantation outcomes after T cell-replete haploidentical transplant among patients given peripheral blood stem cell grafts $(n=238)$. Similar curves to Fig. 1

limited to PBSC recipients showed that the HRs of KIR ligand mismatching for relapse, NRM, LFS, and OS were $1.97(P=0.005), 1.30(P=0.41), 1.60(P=0.02)$, and 1.60 $(P=0.03)$, respectively. No similar significant difference was identified in BM recipients, with a 2-year OS of $44.7 \%$ (34.6-54.8) and 45.1\% (32.4-57.9) after KIR ligand-matched and KIR ligand-mismatched transplants, respectively $(P=$ $0.93)$. There was no significant difference in the KIR ligandmismatching effect in the subgroup analysis according to conditioning intensity or disease status at SCT (data not shown).

\section{Discussion}

Haploidentical transplant with PTCy is increasingly used as a valid transplantation approach in acute leuekmia [6]. The current study confirms in a relatively large multicenter registry study of 444 patients with acute leukemia, the feasibility and relatively favorable outcome of this approach. The 2-year survival rates of $67 \%, 57 \%$, and $29 \%$ in patients in CR1, CR2, and active disease, respectively, compared with the survival rates expected after matched donor transplants. Similarly, a CIBMTR study of 192 patients with AML following haploidentical transplant with PTCy showed a 3-year OS of $45 \%$ that was not different from a comparative group of unrelated donor transplants [25]. Other, smaller studies suggested similar trends [26-28]. Several donor, conditioning regimen, and stem cell source factors can be manipulated attempting in improving outcome. The degree of HLA matching and the specific HLA disparities are not associated with transplantation outcomes [29, 30]. However, the current study shows that KIR ligand mismatching in the graft-versus-host direction, as predicted by missing recipient HLA KIR ligands that are present in the donor (missing self model) is associated with increased relapse rate and worse survival after transplantation, especially when PBSCs are used as stem cell source.

The Perugia group has clearly shown that in the context of extensive $\mathrm{T}$ cell depletion, high stem cell dose, and no post-transplant immune suppression, NK alloreactivity as predicted by the missing self model reduces the risk of relapse and markedly improve survival for patients with AML but not ALL $[13,14]$. NK alloreactivity also reduced the rate of GVHD by eliminating host antigen-presenting cells. Alloreactive $\mathrm{T}$ cells persisted for up to 12 months before becoming tolerized to the recipient. Activating KIR further enhanced the benefit of KIR ligand mismatching, mostly by reducing NRM [31]. 
Contradictory results were reported in haploidentical transplants using less vigorous $\mathrm{T}$ cell depletion. Bishara et al. [32] reported that following a regimen allowing a somewhat larger $\mathrm{T}$ cell content, NK alloreactivity was associated with increased rates of acute GVHD and NRM, and poorer OS, although with similar engraftment and relapse rates. Activating KIRs also increased the risk of GVHD. These authors suggested that the benefit of NK alloreactivity may be less clear in the presence of GVHD caused by residual donor T cells. Cooley et al. [33] have shown in the context of unrelated donor transplants that KIR reconstitution and NK cell function are adversely affected by $\mathrm{T}$ cells in the graft.

There is only limited and emerging data on the role of NK alloreactivity in non- $T$ cell-depleted haploidentical transplants. Russo et al. [17] explored the dynamics of NK cell reconstitution in a group of 17 recipients of haploidentical SCT with PTCy. They showed robust proliferation of donor-derived NK cells, with a mature phenotype, immediately after transplant. However, within days after the infusion of PTCy there was a marked reduction of proliferating NK cells including single KIR positive that include alloreactive NK cells. A second wave of reconstituting NK cells started appearing about 2 weeks after SCT. These cells were predominantly with an immature phenotype and with an impaired antileukemic effect compared with their mature donor counterparts. The phenotypic recovery of mature NK cells stemming from engrafting donor stem cells took several months to 1 year after transplant. As a consequence, in an extended series of 99 haploidentical transplants with PTCy, no significant survival difference was found between patients with or without predicted NK alloreactivity. Interestingly, patients with rapid reconstitution of mature phenotype, including expression of KIR, had a better outcome.

The Chinese group, using ATG-based intensive immune suppression with G-CSF mobilized BM and PBSC, have shown that KIR ligand mismatching as predicted by the missing self model was associated with higher relapse rates and worst survival [18]. KIR ligand mismatching was associated with higher rates of acute GVHD, especially in the group given a higher $\mathrm{T}$ cell content within the graft, but in all NRM was similar. These data suggest that the beneficial NK alloreactivity may be inhibited by the large dose of $\mathrm{T}$ cells given in this protocol. The Chinese group further showed that patients presenting HLA class I ligands for donor inhibitory KIRs had more functional NK effector cells when tested against K562 cell lines and primary leukemia cells [19]. During maturation, NK cell require recognition of their self KIR ligand to acquire full functionality in a process called licensing $[15,16]$. While most studies have shown that NK cell licensing after SCT is determined by donor cells [34], the Chinese group data suggest that in their transplant setting host cells are promoting NK cell licensing and thus KIR ligand matching rather than mismatching protects from relapse. The contradictory results with the Perugia group may be explained by the assumption that a high stem cell dose may favor an environment where NK cells are licensed by donor cells [20]. Thus, the Russo study showed that PTCy eliminated the majority of mature alloreactive NK cells transferred within the graft, thus blunting the favorable impact of KIR

ligand mismatching. The Chinese data further support a negative effect of KIR ligand mismatching by impairing NK licensing and rapid NK cell reconstitution after transplant.

Symons et al. [21] reported the NK effect in a group of 86 patients with various hematological malignancies, given nonmyeloablative haploidentical BM transplants with PTCy, in the Johns Hopkins University. In this group, KIR ligand mismatching was associated with improved relapse rate, similar NRM, and better survival rates. Patients with

homozygous A haplotypes had a better outcome if the donor had at least one B haplotype. NK mismatching was defined as any mismatch in KIR genes, but the more common missing self or missing ligand models were not associated with outcome.

Our results are more similar to the Chinese data using ATG-based conditioning than to the Johns Hopkins data using PTCy. Differences in patient characteristics, conditioning regimens, graft content, and post-transplant immune-suppressive therapy may explain these differences. In particular, our study used PBSC in $46 \%$ of patients, a subset where the adverse effect of KIR ligand mismatching was more evident. The Chinese group used PBSC with G-CSF mobilized BM in all patients, and the Johns Hopkins group used BM exclusively. T cell content of the graft may have a major contribution to these different observations. PTCy depletes alloreactive T cells and NK cells that become activated against host antigens in the early days after transplantation. As discussed activated $\mathrm{T}$ cells may interfere with NK activity in T cell-replete transplant, especially when administered in a larger $\mathrm{T}$ cell dose. Donor regulatory $\mathrm{T}$ cells (T-regs) are resistant to PTCy, owing to increased expression of aldehyde dehydrogenase, the enzyme primarily responsible for detoxification of cyclophosphamide [35]. T-reg expansion or predominance is essential for the PTCy effect [8]. However, pre-clinical studies suggest active cross-talk between NK cells and Tregs. T-regs can prevent NK cytotoxicity and cytokine production [36]. This complex interplay may have an effect on the relative role of NK cells in the different transplantation settings. Similar to the experience in T cell-depleted transplant, the NK effect was less evident in ALL than in AML. Overall outcome was also less favorable in ALL; however, haploidentical transplant is a valid treatment option in ALL [37]. 
In conclusion, $\mathrm{T}$ cell-replete haploidentical transplantation with PTCy is a feasible and effective approach in patients with acute leukemia with expected outcomes that are similar to HLA-matched donors. Unlike haploidentical transplants with $\mathrm{T}$ cell depletion, there is no evidence that selecting NK alloreactive donors provide better outcome in the T cell-replete transplant with PTCy setting. KIR ligand mismatching may even need to be avoided when PBSCs are selected as the stem cell source.

Acknowledgements We would like to thank all investigators and data managers in the EBMT participating centers for their dedicated patient care.

\section{Compliance with ethical standards}

Conflict of interest The authors declare that they have no conflict of interest.

\section{References}

1. Beatty PG, Clift RA, Mickelson EM, Nisperos BB, Flournoy N, Martin PJ, et al. Marrow transplantation from related donors other than HLA-identical siblings. N Engl J Med. 1985;313:76571.

2. Anasetti C, Amos D, Beatty PG, Appelbaum FR, Bensinger W, Buckner CD, et al. Effect of HLA compatibility on engraftment of bone marrow transplants in patients with leukemia or lymphoma. N Engl J Med. 1989;320:197-204.

3. Aversa F, Terenzi A, Tabilio A, Falzetti F, Carotti A, Ballanti S, et al. Full haplotype-mismatched hematopoietic stem-cell transplantation: a phase II study in patients with acute leukemia at high risk of relapse. J Clin Oncol. 2005;23:3447-54.

4. Luznik L, O'Donnell PV, Symons HJ, Chen AR, Leffell MS, Zahurak M, et al. HLA-haploidentical bone marrow transplantation for hematologic malignancies using nonmyeloablative conditioning and high-dose, posttransplantation cyclophosphamide. Biol Blood Marrow Transplant. 2008;14:641-50.

5. Huang XJ, Liu DH, Liu KY, Xu LP, Chen H, Han W, et al. Treatment of acute leukemia with unmanipulated HLA-mismatched/haploidentical blood and bone marrow transplantation. Biol Blood Marrow Transplant. 2009;15:257-65.

6. Passweg JR, Baldomero H, Bader P, Bonini C, Duarte RF, Dufour $\mathrm{C}$, et al. Use of haploidentical stem cell transplantation continues to increase: the 2015 European Society for Blood and Marrow Transplant activity survey report. Bone Marrow Transplant. 2017;52:811-7.

7. Mancusi A, Ruggeri L, Velardi A. Haploidentical hematopoietic transplantation for the cure of leukemia: from its biology to clinical translation. Blood. 2016;128:2616-23.

8. Kanakry CG, Fuchs EJ, Luznik L. Modern approaches to HLAhaploidentical blood or marrow transplantation. Nat Rev Clin Oncol. 2016;13:10-24.

9. Chang YJ, Luznik L, Fuchs EJ, Huang XJ. How do we choose the best donor for T-cell-replete, HLA-haploidentical transplantation? J Hematol Oncol. 2016;9:35.

10. McCurdy SR, Fuchs EJ. Selecting the best haploidentical donor. Semin Hematol. 2016;53:246-51.

11. Ciurea SO, Champlin RE. Donor selection in T cell-replete haploidentical hematopoietic stem cell transplantation: knowns, unknowns, and controversies. Biol Blood Marrow Transplant. 2013;19:180-4.
12. Wang Y, Chang YJ, Xu LP, Liu KY, Liu DH, Zhang XH, et al. Who is the best donor for a related HLA haplotype-mismatched transplant? Blood. 2014;124:843-50.

13. Ruggeri L, Capanni M, Urbani E, Perruccio K, Shlomchik WD, Tosti A, et al. Effectiveness of donor natural killer cell alloreactivity in mismatched hematopoietic transplants. Science. 2002;295:2097-100.

14. Ruggeri L, Mancusi A, Capanni M, Urbani E, Carotti A, Aloisi T, et al. Donor natural killer cell allorecognition of missing self in haploidentical hematopoietic transplantation for acute myeloid leukemia: challenging its predictive value. Blood. 2007;110:433-40.

15. Babor F, Fischer JC, Uhrberg M. The role of KIR genes and ligands in leukemia surveillance. Front Immunol. 2013;4:27.

16. Handgretinger R, Lang P, André MC. Exploitation of natural killer cells for the treatment of acute leukemia. Blood. 2016;127:3341-9.

17. Russo A, Oliveira G, Berglund S, Greco R, Gambacorta V, Cieri $\mathrm{N}$, et al. NK cell recovery after haploidentical HSCT with posttransplant cyclophosphamide: dynamics and clinical implications. Blood. 2018;131:247-62.

18. Huang XJ, Zhao XY, Liu DH, Liu KY, Xu LP. Deleterious effects of KIR ligand incompatibility on clinical outcomes in haploidentical hematopoietic stem cell transplantation without in vitro T-cell depletion. Leukemia. 2007;21:848-51.

19. Zhao XY, Chang YJ, Zhao XS, Xu LP, Zhang XH, Liu KY, et al. Recipient expression of ligands for donor inhibitory KIRs enhances NK cell function to control leukemic relapse after haploidentical transplantation. Eur J Immunol. 2015;45: 2396408.

20. Zhao XY, Chang YJ, Huang XJ. Conflicting impact of alloreactive NK cells on transplantation outcomes after haploidentical transplantation: do the reconstitution kinetics of natural killer cells create these differences? Biol Blood Marrow Transplant. 2011;17: $1436-42$.

21. Symons HJ, Leffell MS, Rossiter ND, Zahurak M, Jones RJ, Fuchs EJ. Improved survival with inhibitory killer immunoglobulin receptor (KIR) gene mismatches and KIR haplotype B donors after nonmyeloablative, HLA-haploidentical bone marrow transplantation. Biol Blood Marrow Transplant. 2010;16: 533-42.

22. Bacigalupo A, Ballen K, Rizzo D, Giralt S, Lazarus H, Ho V, et al. Defining the intensity of conditioning regimens: working definitions. Biol Blood Marrow Transplant. 2009;15: 1628-33.

23. Kaplan EL, Meier P. Nonparametric estimation from incomplete observations. J Am Stat Assoc. 1958;53:457-81.

24. Gooley TA, Leisenring W, Crowley J, Storer BE. Estimation of failure probabilities in the presence of competing risks: new representations of old estimators. Stat Med. 1999;18: 695706.

25. Ciurea SO, Zhang MJ, Bacigalupo AA, Bashey A, Appelbaum FR, Aljitawi OS, et al. Haploidentical transplant with posttransplant cyclophosphamide vs matched unrelated donor transplant for acute myeloid leukemia. Blood. 2015;126:1033-40.

26. Bashey A, Zhang X, Sizemore CA, Manion K, Brown S, Holland HK, et al. T-cell-replete HLA-haploidentical hematopoietic transplantation for hematologic malignancies using posttransplantation cyclophosphamide results in outcomes equivalent to those of contemporaneous HLA-matched related and unrelated donor transplantation. J Clin Oncol. 2013;31:1310-6.

27. Di Stasi A, Milton DR, Poon LM, Hamdi A, Rondon G, Chen J, et al. Similar transplantation outcomes for acute myeloid leukemia and myelodysplastic syndrome patients with haploidentical versus 10/10 human leukocyte antigen-matched unrelated and related donors. Biol Blood Marrow Transplant. 2014;20: 1975-81. 
28. Piemontese S, Ciceri F, Labopin M, Arcese W, Kyrcz-Krzemien S, Santarone S, et al. A comparison between allogeneic stem cell transplantation from unmanipulated haploidentical and unrelated donors in acute leukemia. J Hematol Oncol. 2017;10:24.

29. Kasamon YL, Luznik L, Leffell MS, Kowalski J, Tsai HL, Bolaños-Meade J, et al. Nonmyeloablative HLA-haploidentical bone marrow transplantation with high-dose posttransplantation cyclophosphamide: effect of HLA disparity on outcome. Biol Blood Marrow Transplant. 2010;16:482-9.

30. Lorentino F, Labopin M, Fleischhauer K, Ciceri F, Mueller CR, Ruggeri A, et al. The impact of HLA matching on outcomes of unmanipulated haploidentical HSCT is modulated by GVHD prophylaxis. Blood Adv. 2017;1:669-80.

31. Mancusi A, Ruggeri L, Urbani E, Pierini A, Massei MS, Carotti A, et al. Haploidentical hematopoietic transplantation from KIR ligand-mismatched donors with activating KIRs reduces nonrelapse mortality. Blood. 2015;125:3173-82.

32. Bishara A, De Santis D, Witt CC, Brautbar C, Christiansen FT, Or $\mathrm{R}$, et al. The beneficial role of inhibitory KIR genes of HLA class I NK epitopes in haploidentically mismatched stem cell allografts may be masked by residual donor-alloreactive $\mathrm{T}$ cells causing GVHD. Tissue Antigens. 2004;63:204-11.
33. Cooley S, McCullar V, Wangen R, Bergemann TL, Spellman S, Weisdorf DJ, et al. KIR reconstitution is altered by $\mathrm{T}$ cells in the graft and correlates with clinical outcomes after unrelated donor transplantation. Blood. 2005; 106:4370-6.

34. Haas P, Loiseau P, Tamouza R, Cayuela JM, Moins-Teisserenc H, Busson M, et al. NK cell education is shaped by donor HLA genotype after unrelated allogeneic hematopoietic stem cell transplantation. Blood. 2011;117:1021-9.

35. Kanakry CG, Ganguly S, Luznik L. Situational aldehyde dehydrogenase expression by regulatory $\mathrm{T}$ cells may explain the contextual duality of cyclophosphamide as both a proinflammatory and tolerogenic agent. Oncoimmunology. 2015;4: e974393.

36. Verneris MR. Natural killer cells and regulatory T cells: how to manipulate a graft for optimal GVL. Hematology Am Soc Hematol Educ Program 2013; 335-41.

37. Santoro N, Ruggeri A, Labopin M, Bacigalupo A, Ciceri F, Gülbaş Z, et al. Unmanipulated haploidentical stem cell transplantation in adults with acute lymphoblastic leukemia: a study on behalf of the Acute Leukemia Working Party of the EBMT. J Hematol Oncol. 2017;10:113. 